\title{
miR-31-5p may enhance the efficacy of chemotherapy with Taxol and cisplatin in TNBC
}

\author{
XIAOWEI SHEN $^{1 *}$, JIAQI LEI $^{1 *}$ and LEI DU ${ }^{2}$ \\ ${ }^{1}$ Department of General Surgery, Zhongshan Hospital Qingpu Branch, Fudan University, Shanghai 200092; ${ }^{2}$ Department of \\ General Surgery, Shuguang Hospital, Shanghai University of Traditional Chinese Medicine, Shanghai 201203, P.R. China
}

Received May 30, 2018; Accepted July 19, 2019

DOI: $10.3892 /$ etm.2019.8191

\begin{abstract}
The limited efficacy of chemotherapy with Taxol (TAX) and cisplatin (DDP) in triple-negative breast cancer (TNBC) has prompted the investigation of combined therapies. Previous studies demonstrated that microRNA (miR)-31-5p is involved in various biological processes. In the present study, it was hypothesized that the overexpression of miR-31-5p may enhance the efficacy of chemotherapy. The expression levels of miR-31-5p in the TNBC cell lines MDA-MB-231 and MDA-MB-468 were measured using reverse transcription-quantitative PCR following transfection with miR-31-5p mimic or inhibitor. A Cell Counting Kit- 8 and flow cytometry assays suggested that the overexpression of miR-31-5p inhibited cell proliferation and promoted apoptosis, and these effects were reversed by transfecting a miR-31-5p inhibitor into MDA-MB-231 and MDA-MB-468 cells. Furthermore, the overexpression of miR-31-5p increased the sensitivity of cells to chemotherapy, which exhibited an increase in apoptosis and in the expression level of Bax, and a decrease in the expression level of Bcl-2. Chemotherapy resistance induced by miR-31-5p inhibitor could be reversed by inhibiting the AKT signaling pathway in MDA-MB-231 and MDA-MB-468 cells. In conclusion, the present preclinical results indicated that targeting miR-31-5p may enhance the efficacy of TAX- and DDP-mediated chemotherapy in TNBC.
\end{abstract}

\section{Introduction}

Breast cancer is a common gynecologic cancer worldwide (1). Low expression of human epidermal growth factor receptor 2 (HER2), progesterone receptor (PR) and estrogen receptor

Correspondence to: Professor Lei Du, Department of General Surgery, Shuguang Hospital, Shanghai University of Traditional Chinese Medicine, 528 Zhangheng Road, Shanghai 201203, P.R. China

E-mail: 18930516400@sina.cn

*Contributed equally

Key words: triple-negative breast cancer, microRNA-31, Taxol, cisplatin, AKT
(ER) are the main characteristics of TNBC (2). TNBC accounts for $10-15 \%$ of breast carcinomas, which constitute $\sim 80 \%$ of all 'basal-like tumors' (3). There are many risk factors for TNBC, including the lack of breastfeeding, high parity, high body mass index and young age at menarche (4). The majority of tumor exhibiting a BRCAl-mutation belong to the TNBC subtype (5). Compared with other subtypes of breast cancer, TNBC has a poor prognosis and tends to recur more frequently (6). Although a previous study showed that TNBC is sensitive to chemotherapy, sensitive patients only represent a minority of all patients with TNBC (7). Although the survival rate of breast cancer has increased significantly in recent years, there is still no effective treatment for TNBC (8). Currently, breast cancer treatments target ER, PR or HER2, and it is therefore essential to identify novel biomarkers that may predict tumor progression and that can be used as potential therapeutic targets (9-12).

MicroRNAs (miRNAs) are a class of small non-coding RNAs that can regulate gene expression by triggering translation repression or RNA degradation of the target mRNAs (13). Dysregulation of miRNAs or the expression of mutant miRNAs in human diseases including cancer, suggest that miRNAs may act as oncogenes or tumor suppressors (14-18). Among the differentially expressed miRNAs, miRNA (miR)-155-5p, miR-21-3p, miR-181a-5p, miR-181b-5p and miR-183-5p are significantly upregulated in TNBC, whereas miR-10b-5p, miR-451a, miR-125b-5p, miR-31-5p, miR-195-5p and miR-130a-3p are downregulated (7). In addition, miRNAs that act as metastasis suppressors in breast cancer include miR-17/20, miR-22, miR-30, miR-31, miR-126, miR-145, miR-146, miR-205, miR-206 and let-7 (19). However, the mechanism underlying miR-31-5p function in TNBC remains unclear. miR-31 is involved in many biological processes, including bone formation (20), embryonic development (21) and myogenesis (22). In addition, miR-31 has been reported to promote spermatogenesis and to facilitate embryonic implantation $(23,24)$. Dysregulation of miR-31 has also been found in various human diseases, including cancer and autoimmune diseases (21). Repression of miR-31 was identified in breast cancer, suggesting that miR-31 may serve as a tumor suppressor (25). miR-31 inhibition has been identified in leukemia patients, and it was shown that miR-31 can inhibit NF- $\mathrm{B}$ signaling by suppressing mitogen-activated protein kinase kinase kinase 14 (26). Similarly, patients with 
hepatocellular carcinoma exhibit downregulated levels of miR-31 (27). By contrast, miR-31 was also found to be upregulated in certain types of cancer; in colorectal cancer, miR-31 acts as an oncogenic miRNA $(28,29)$. In lung cancer, miR-31 directly regulates tumor-suppressing genes, such as protein phosphatase 2 regulatory subunit $\mathrm{B} \alpha$, large tumor suppressor kinase 2 and BRCA1 associated protein $1(30,31)$.

Although previous studies have revealed important roles for miR-31 in different cancer types (20-22,32), the role of miR-31 in TNBC remains unclear. The aim of the present study was to investigate the role of miR-31 in TNBC by overexpressing or silencing miR-31 in TNBC cell lines.

\section{Materials and methods}

Cell line and cell culture. The human TNBC cell line MDA-MB-231 was obtained from The Cell Bank of the Chinese Academy of Sciences and cultured in DMEM (HyClone; GE Healthcare Life Sciences) containing 10\% FBS, $100 \mathrm{U} / \mathrm{ml}$ penicillin and $100 \mu \mathrm{g} / \mathrm{ml}$ streptomycin (all Gibco; Thermo Fisher Scientific, Inc.). Cells were incubated at $37^{\circ} \mathrm{C}$ in a humidified incubator with $5 \% \mathrm{CO}_{2}$.

Cells were transfected with miR-31-5p mimics or miR-31-5p inhibitors for $48 \mathrm{~h}$ at $37^{\circ} \mathrm{C}$, and then treated with $50 \mu \mathrm{M}$ Taxol (TAX; Aladdin Biochemical Technology, Co., Ltd.) for $24 \mathrm{~h}, 50 \mu \mathrm{M}$ cisplatin (DDP; Sigma-Aldrich; Merck $\mathrm{KGaA}$ ) for $24 \mathrm{~h}$ or $20 \mu \mathrm{M} \mathrm{LY} 294002$ (Selleck Chemicals), an antagonist of the AKT pathway, for $48 \mathrm{~h}$ at $37^{\circ} \mathrm{C}$, respectively. Following treatments, cells were used for the following experiments.

miR-31-5p mimic and inhibitor. The miR-31-5p mimic and miR-31-5p inhibitor were used to overexpress or repress the expression level of miR-31-5p. The hsa-miR-31-5p mimic (final concentration, $5 \mathrm{nM}$ ), inhibitor (final concentration, $50 \mathrm{nM}$ ) and negative controls ( $\mathrm{NCs}$; final concentration, $5 \mathrm{nM}$ ) were synthesized by GenePharma. The sequences of the miR-31-5p mimic, inhibitor and NC are presented in Table I. Cells were plated in six-well plates and transfected with the mimic, inhibitor and NC using Lipofectamine 2000 (Invitrogen; Thermo Fisher Scientific, Inc.) according to the manufacturer's protocol. Cells were harvested for further experimentation after $48 \mathrm{~h}$.

Reverse transcription-quantitative PCR (RT-qPCR). Treated cells were rinsed twice with PBS, and RNA was extracted using TRIzol Reagent (Invitrogen; Thermo Fisher Scientific, Inc.) according to the manufacturer's protocol. cDNA was synthesized using a Moloney murine leukemia virus reverse transcriptase kit (Promega Corporation) on an ABI 7300 system (Applied Biosystems; Thermo Fisher Scientific, Inc.) using the following protocol: $37^{\circ} \mathrm{C}$ for $60 \mathrm{~min}, 85^{\circ} \mathrm{C}$ for $5 \mathrm{~min}$ and $4^{\circ} \mathrm{C}$ for $5 \mathrm{~min}$. RT-qPCR was performed using a SYBR Green qPCR kit (Thermo Fisher Scientific, Inc.) and an ABI 7300 system using the following protocol: $95^{\circ} \mathrm{C}$ for $10 \mathrm{~min}$, 40 cycles of $95^{\circ} \mathrm{C}$ for $15 \mathrm{sec}$ and $60^{\circ} \mathrm{C}$ for $45 \mathrm{sec}, 95^{\circ} \mathrm{C}$ for $15 \mathrm{sec}, 60^{\circ} \mathrm{C}$ for $1 \mathrm{~min}$, and $4^{\circ} \mathrm{C}$ for $10 \mathrm{~min}$. Gene expression levels were normalized to the expression level of U6 and calculated using the $2^{-\Delta \Delta \mathrm{Cq}}$ method (33). The sequences of the primers used for the RT-qPCR analysis are presented in Table I.
Cell proliferation. A Cell Counting Kit-8 assay (CCK-8; Beyotime Institute of Biotechnology) was used to examine cell proliferation. Treated cells were plated into 96-well plate (2,000 cells/well). After 24, 48 and $72 \mathrm{~h}$ of all treatments, the medium was replaced with DMEM containing 10\% CCK-8 solution and the cells were incubated for $1 \mathrm{~h}$ at $37^{\circ} \mathrm{C}$. Following incubation, the absorbance was detected using an automatic microplate reader (Bio-Rad Laboratories, Inc.) at a wavelength of $450 \mathrm{~nm}$. Experiments were performed in triplicate.

Cell apoptosis. An Annexin V/propidium iodide (PI) apoptosis detection kit (BD Biosciences) was used to measure the cell apoptosis according to the manufacturer's protocol. Cells were plated into six-well plates and then transfected and/or treated with various drugs. Cells were rinsed twice with cold PBS and incubated in the staining buffer, which was included in the kit. Then, the cells were stained with Annexin V and PI for $15 \mathrm{~min}$ at $37^{\circ} \mathrm{C}$ in the dark and then evaluated by flow cytometry (Accuri C6; BD Biosciences). Experiments were performed in triplicate.

Western blot analysis. Whole protein was extracted from MDA-MB-231 cells after two washes with cold PBS using RIPA lysis buffer (Beyotime Institute of Biotechnology). Protein concentration was measured by BCA kit (Bio-Rad Laboratories, Inc.). A total of $20 \mu \mathrm{g}$ protein from each group was and then separated by SDS-PAGE on $10 \%$ gels, and after separation the proteins were transferred to nitrocellulose membranes (EMD Millipore). After blocking with PBST containing 5\% BSA (Beyotime Institute of Biotechnology), the blots were incubated with the appropriate primary antibodies at $4{ }^{\circ} \mathrm{C}$ overnight and horseradish peroxidase-conjugated secondary antibodies (cat. no. A0216; 1:1,000 dilution; Beyotime Institute of Biotechnology) at room temperature for $1 \mathrm{~h}$. The primary antibodies used (dilution, 1:1,000) were the following: Anti-P-glycoprotein (P-gp; cat. no. ab103477), anti-Bcl-2 (cat. no. ab32124), and anti-Bax (cat. no. ab32503; all Abcam), anti-AKT (cat. no. 4685), anti-phosphorylated (p)-AKT (cat. no. 4060) and anti-GAPDH (cat. no. 5174; all Cell Signaling Technologies, Inc.). Signals were detected using an ECL kit (EMD Millipore). Bands were analyzed with ImageJ 5.0 (National Institutes of Health) and GAPDH was used as the loading control.

Statistics. All the experiments were performed $\geq 3$ times. Data are presented as the mean \pm SD. The statistical differences between the control and treatment groups were determined using ANOVA followed by a Student-Newman-Keuls test. Data were analyzed using GraphPad Prism 6.0 (GraphPad Software, Inc.). $\mathrm{P}<0.05$ was considered to indicate a statistically significant difference.

\section{Results}

Overexpression of $m i R-31$ promotes apoptosis and inhibits cell proliferation in TNBC cells. To investigate the role of miR-31-5p in TNBC, MDA-MB-231 and MDA-MB-468 cell lines were selected to examine the effects of altering the expression level of miR-31-5p. The miR-31-5p mimic and miR-31-5p inhibitor were transfected into MDA-MB-231 and MDA-MB-468 cells. 
Table I. Primer, mimic and inhibitor sequences.

Oligonucleotide

Sequences $\left(5^{\prime}-3^{\prime}\right)$

miR-31-5p Primers

F: ACACTCCAGCTGGGAGGCAAGATGCTGGC

R: TGGTGTCGTGGAGTCG

U6 Primers

F: CTCGCTT CGGCAGCACA

R: AACGCTTCACGAATTTGCGT

miR-31-5p mimic

AGGCAAGAUGCUGGCAUAGCU

miR-31-5p mimic NC

UUGUACUACACAAAAGUACUG

miR-31-5p inhibitor

miR-31-5p inhibitor NC

AGCUAUGCCAGCAUCUUGCCU

CAGUACUUUUGUGUAGUACAA

miR, microRNA; NC, negative control.

RT-qPCR was used to detect the efficiency of miR-31-5p overexpression and inhibition. miR-31-5p was dramatically increased and reduced after miR-31-5p mimic and inhibitor transfection, respectively (Fig. 1A). Following the determination of the transfection efficiencies, the effects of miR-31-5p on cell proliferation were examined. Cell Counting Kit- 8 assay was performed to measure cell proliferation and cytotoxicity. Cells transfected with miR-31-5p mimic proliferated more slowly than cells transfected with miR-NC (Fig. 1B). The miR-31-5p inhibitor transfection exhibited opposite effects, as this transfection promoted cell proliferation in MDA-MB-231 and MDA-MB-468 cells. To explore the mechanism underlying miR-31-p function, cells were stained with Annexin-V, and flow cytometry was performed to detect the effects of miR-31 on cell apoptosis. An increased number of PI and Annexin-V double positive cells were found in the group transfected with miR-31-5p mimic, suggesting an increase in cell apoptosis. miR-31-5p inhibitor reduced apoptosis in MDA-MB-231 and MDA-MB-468 cells, in line with the aforementioned results (Fig. 1C). Collectively, the present data suggested that overexpression of miR-31-5p promoted apoptosis and inhibited cell proliferation in MDA-MB-231 and MDA-MB-468 cells. By contrast, inhibition of miR-31-5p expression exhibited the opposite effects on cell proliferation and apoptosis.

miR-31 overexpression increases the sensitivity of TNBC to TAX and DDP treatment. TNBC is an aggressive cancer with a high risk of relapse within the first 3-5 years after the completion of adjuvant chemotherapy treatments (34). The potential role of miR-31-5p in chemotherapy resistance was then investigated. First, the appropriate concentration of each drug was examined. Treatment with TAX and DDP at $50 \mu \mathrm{mol} / 1$ induced cell apoptosis but did not induce cell death in a large portion of the cell population. After transfection with miR-31-5p mimic for $48 \mathrm{~h}, 50 \mu \mathrm{mol} / 1 \mathrm{TAX}$ or DDP were used to treat cells for $48 \mathrm{~h}$. Then, the harvested cells were stained with PI and annexin-V and flow cytometry was performed to detect cell apoptosis. Single treatment with TAX or DDP increased apoptosis, but the effects were increased when combined with miR-31-5p mimic transfection (apoptotic rates: TAX, 25.7 $\pm 0.61 \%$; TAX + mimic, $45.8 \pm 0.52 \%$; DDP, $28.74 \pm 0.74 \%$; and DDP + mimic, $54.8 \pm 0.87 \%$ ) (Fig. 2A).
Then, the underlying mechanisms of miR-31-5p-mediated chemoresistance were investigated. Following various treatments, cells were harvested and western blotting was performed to detect the expression levels of apoptosis-related proteins, including an apoptosis suppressor (Bcl-2) (35) and a positive regulator of apoptosis ( $\mathrm{Bax}$ ) (36). The protein expression level of $\mathrm{P}-\mathrm{gp}$, which is negatively associated with chemotherapy sensitivity (37), was also detected. As presented in Fig. 2B, P-gp expression increased with single treatment with TAX or DDP, but significantly decreased following drug treatments combined with miR-31 mimic transfection. Bcl-2 was decreased after treatment with TAX or DDP and the effects were more significant in cells transfected with miR-31 mimic. Consistently, monotherapy with TAX or DDP significantly increased the protein expression levels of Bax, and the increase was greater following miR-31 mimics transfection. However, the levels of $\mathrm{p}-\mathrm{AKT}$, a tumor proliferation marker (38), showed opposite trends compared with Bax, suggesting decreased proliferation and increased apoptosis following miR-31 mimics transfection (Fig. 2C). Collectively, the synergistic effect of miR-31-5p and TAX or DDP promoted apoptosis in TNBC cells.

Inhibition of miR-31-5p decreases the sensitivity of TNBC to TAX and DDP treatment. To further validate the present findings, cells were transfected with miR-31-5p inhibitor, and flow cytometry and western blotting were performed. The inhibition of miR-31-5p slightly reduced the apoptotic rates induced by single treatment with TAX or DDP (apoptosis rates: TAX, 23.8 $\pm 0.46 \%$; TAX + inhibitor, $16.2 \pm 0.46 \%$; DDP, $28.37 \pm 1.12 \%$; and DDP + inhibitor, $16.63 \pm 0.4 \%$ ) (Fig. 3A). To study the mechanism of miR-31-5p, markers of apoptosis and proliferation were detected by western blotting. Both P-gp and Bcl-2 were significantly increased after combined chemotherapy and transfection of miR-31-5p inhibitor (Fig. 3B). Consistently, treatment with TAX or DDP and transfection of the inhibitor dramatically decreased the levels of Bax. However, the amplification marker p-AKT showed contrasting trends with Bax, suggesting increased proliferation but decreased apoptosis after transfection of miR-31-5p inhibitor (Fig. 3B). Collectively, the present results suggested that inhibition of miR-31-5p reduced the apoptotic rates induced by TAX and 
A

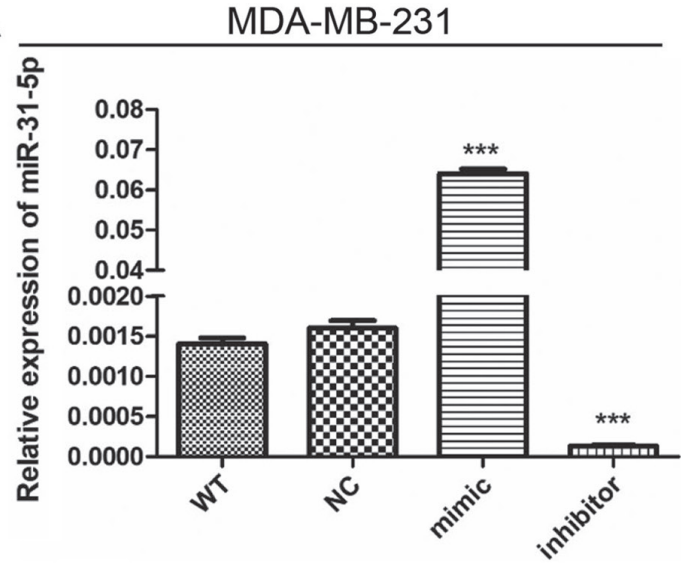

B

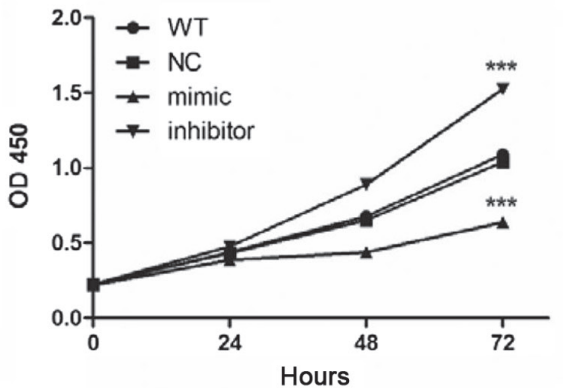

C

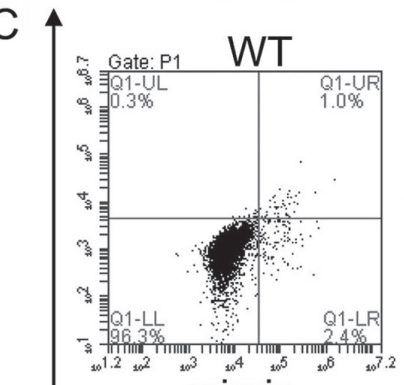

$\bar{\alpha}$
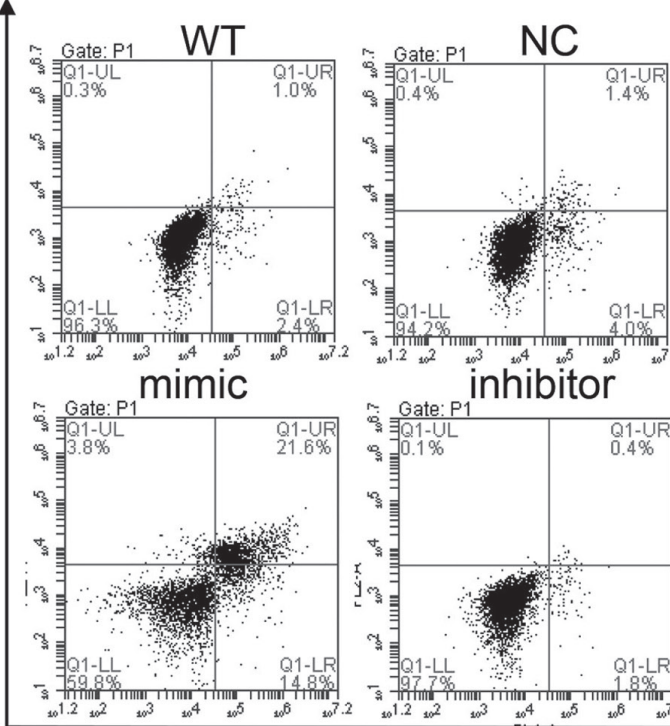

inhibitor
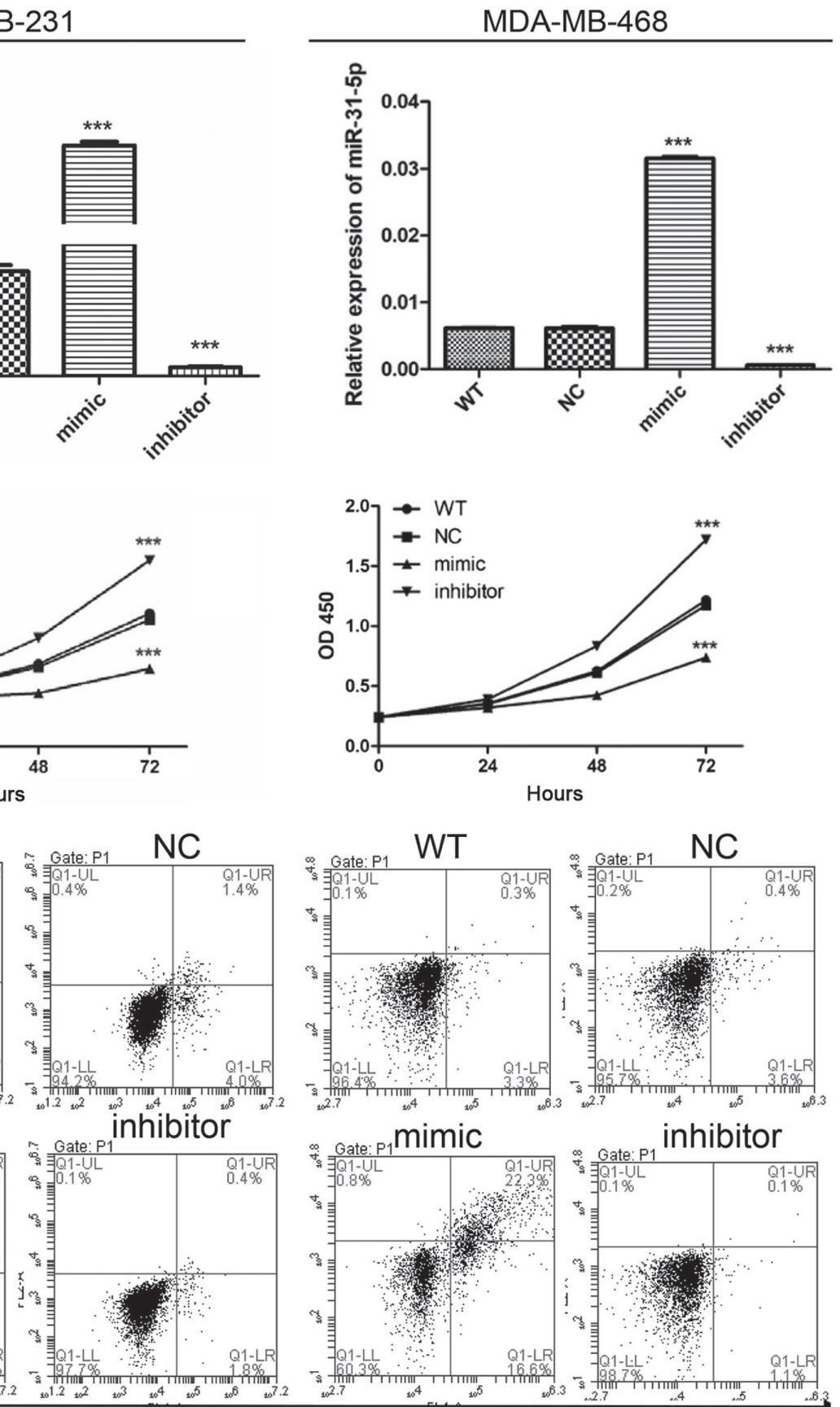

inhibitor

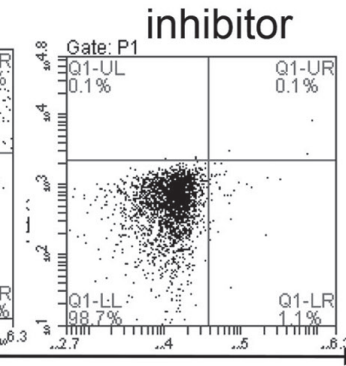

Annexin V
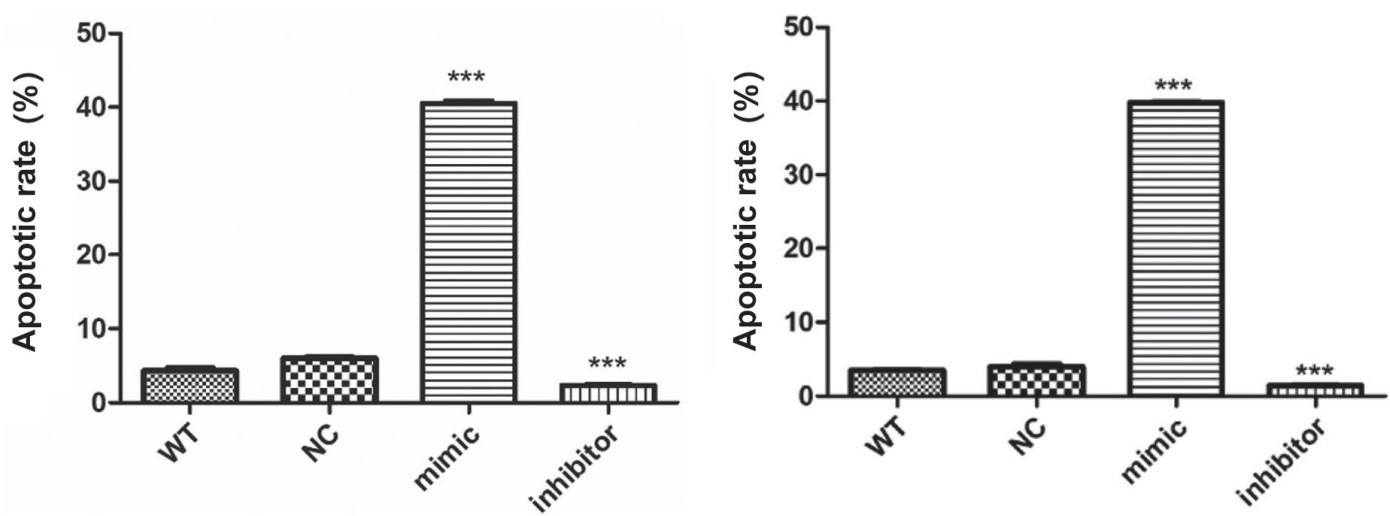

Figure 1. Overexpression of miR-31 promotes apoptosis but inhibits cell proliferation in TNBC cells. (A) Reverse transcription-quantitative PCR was performed to detect the expression level of miR-31-5p following transfection with miR-31-5p mimic or inhibitor. (B) Cell Cycle Kit-8 assay was performed to measure cell proliferation in MDA-MB-231 and MDA-MB-468 cells. (C) Flow cytometry was performed to measure cell apoptosis following staining with annexin-V and PI. ${ }^{* * *}$ P $<0.001$ vs. NC. WT, wild-type; NC, negative control; miR, microRNA; PI, propidium iodide; OD, optical density. 


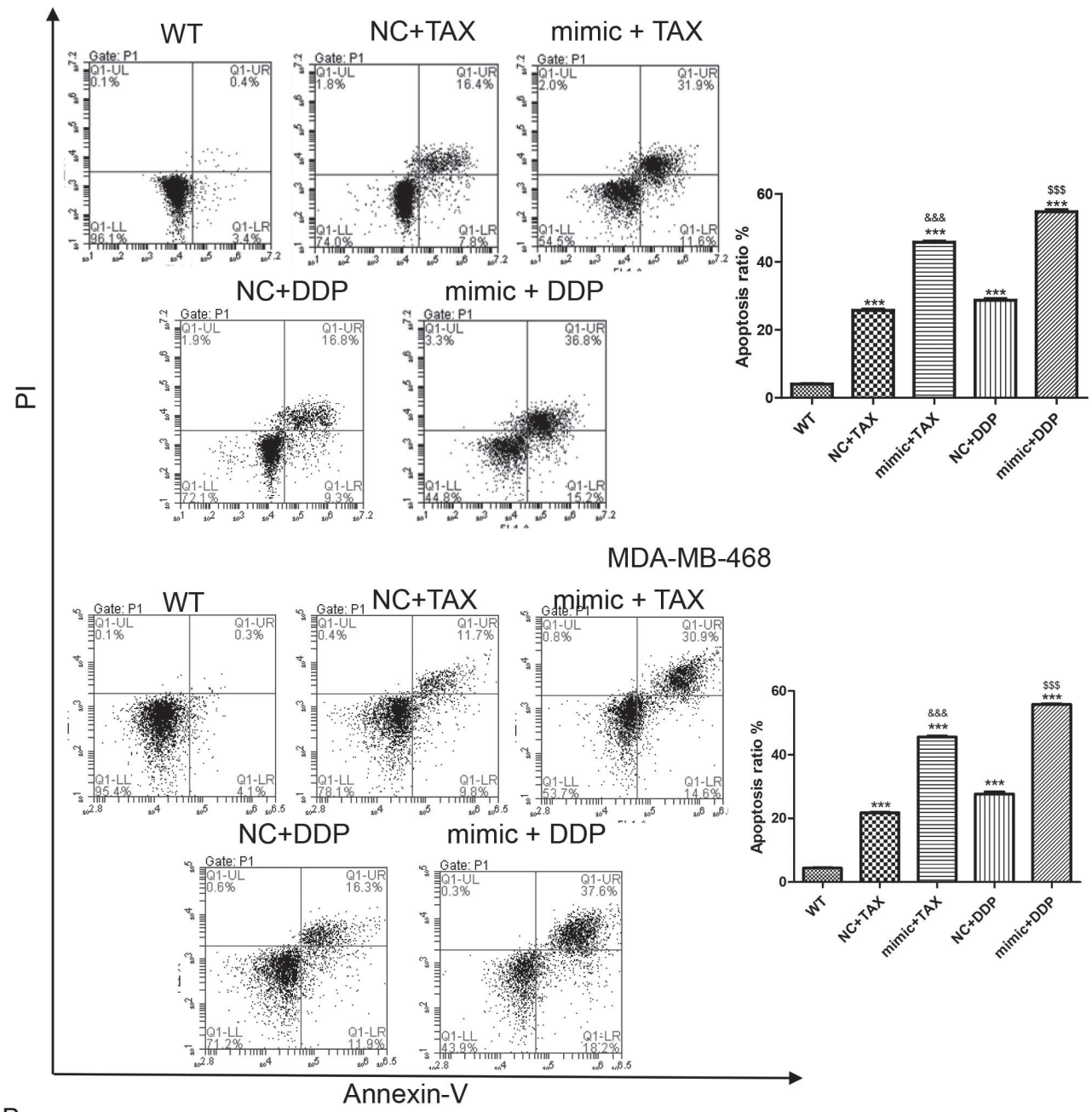

B

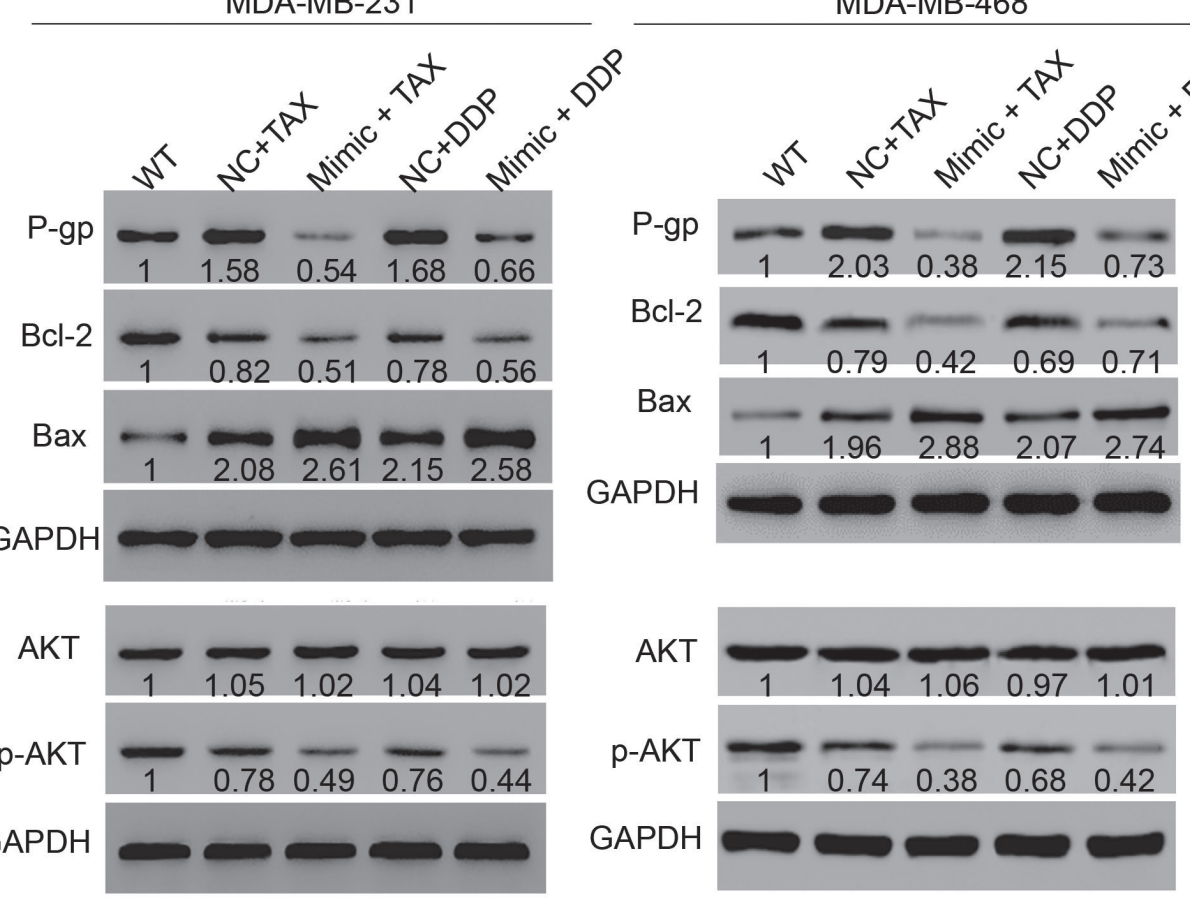

Figure 2. miR-31 overexpression increases the sensitivity of TNBC to TAX and DDP. (A) Flow cytometry was performed to measure cell apoptosis after staining with annexin-V and PI. (B) Western blot analysis was performed to detect the protein expression level of P-gp, Bcl-2 and Bax. Both AKT and p-AKT

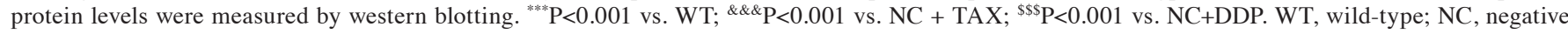
control; TAX, Taxol; DCC, cisplatin; miR, microRNA; PI, propidium iodide; p-, phosphorylated; P-gp, P-glycoprotein. 
A

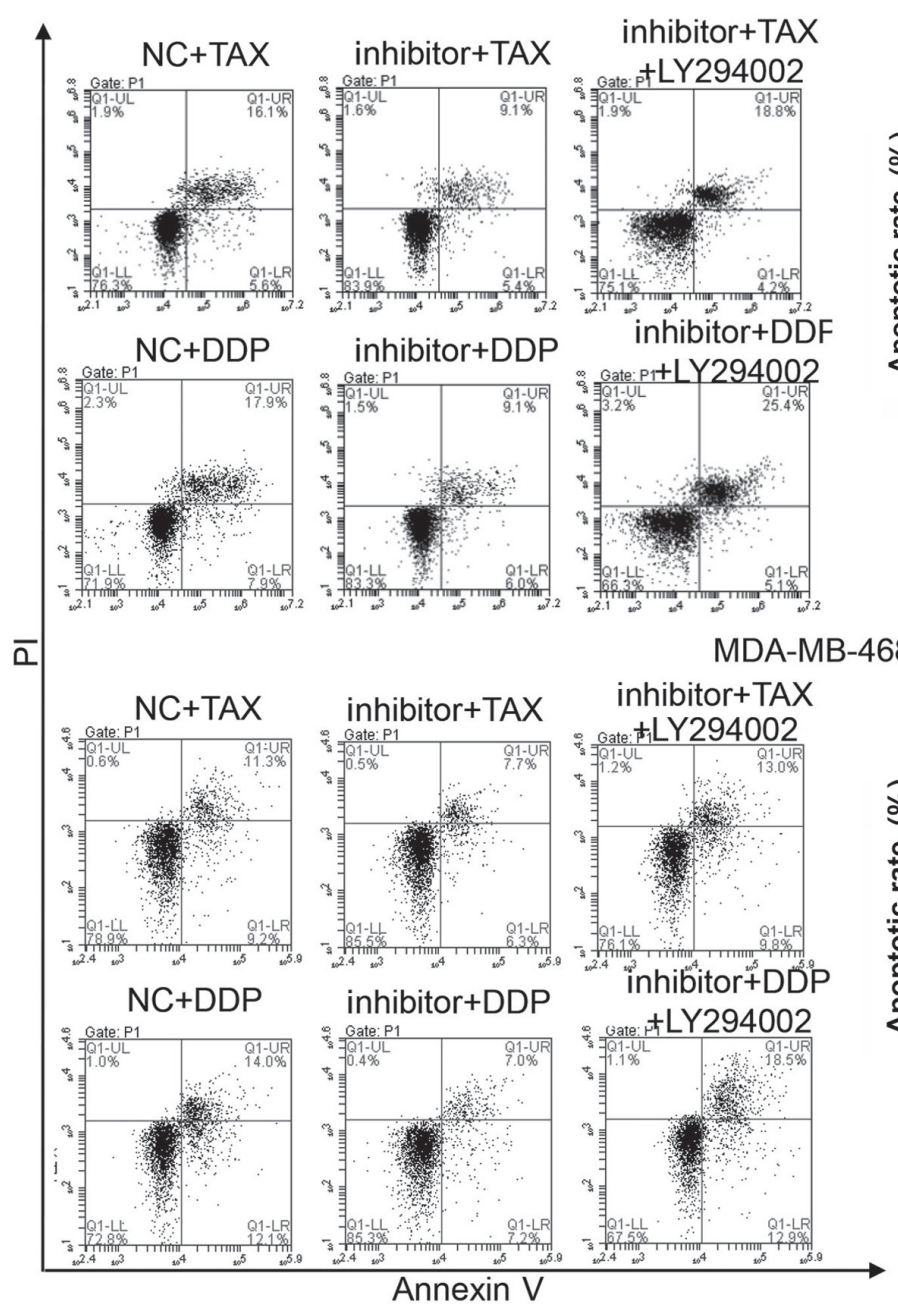

MDA-MB-231
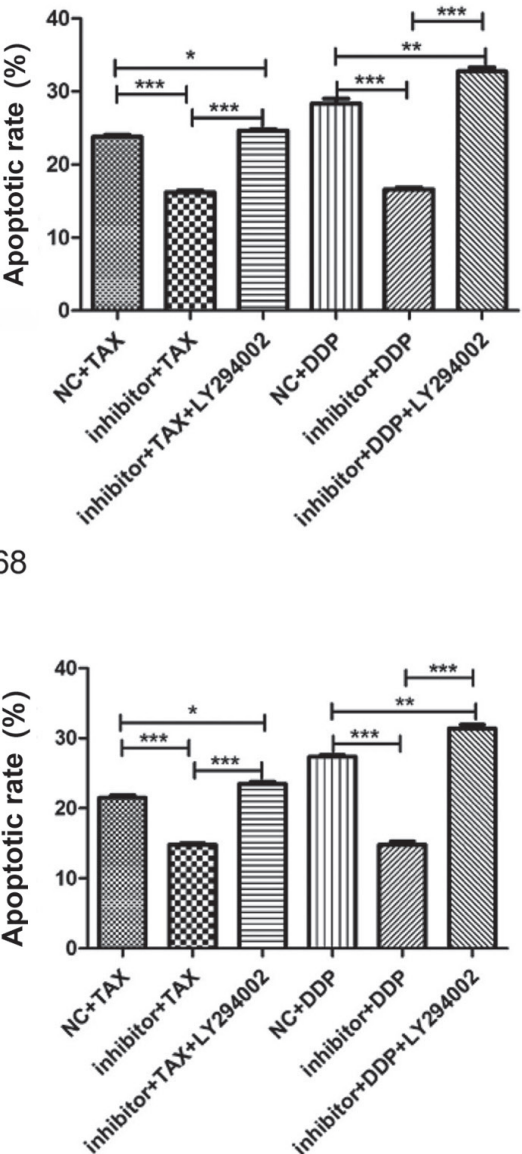

B

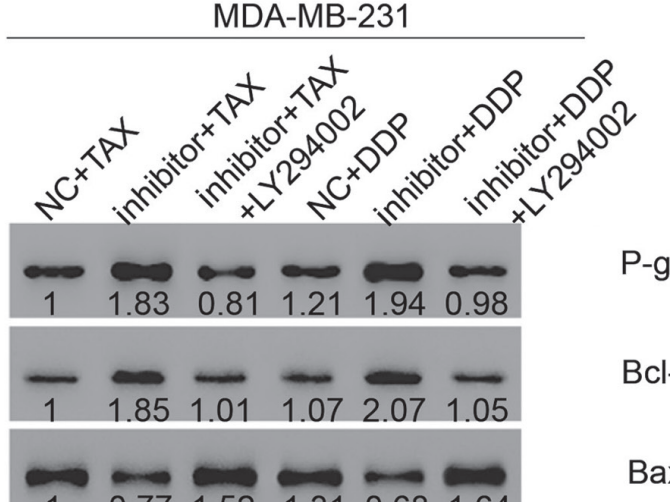

MDA-MB-468

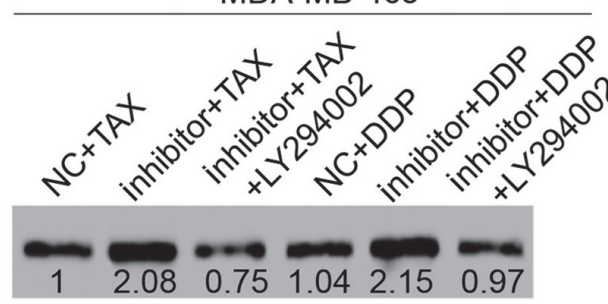

$\mathrm{Bcl}-2$

Bax

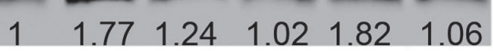

$\begin{array}{llllll}1 & 0.77 & 1.52 & 1.31 & 0.68 & 1.64\end{array}$

GAPDH
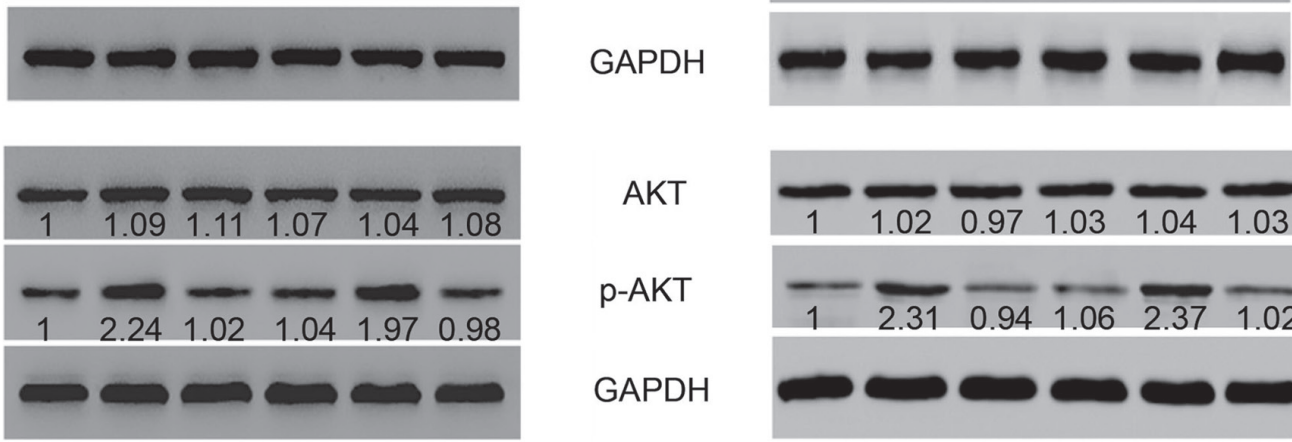

AKT

p-AKT

GAPDH

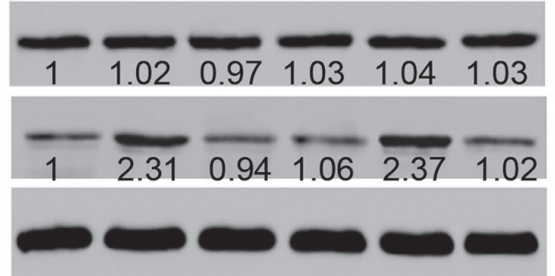

Figure 3. Inhibition of AKT pathway reestablishes the sensitivity to chemotherapy in TNBC cells. (A) Flow cytometry was performed to measure cell apoptosis after staining with annexin-V and PI. (B) Western blotting was performed to detect the protein levels of P-gp, Bcl-2, Bax, AKT and p-AKT. "P<0.05, "* P<0.01, ${ }_{* * * *} \mathrm{P}<0.001$. NC, negative control; TAX, Taxol; DCC, cisplatin; miR, microRNA; p-, phosphorylated; P-gp, P-glycoprotein; PI, propidium iodide. 
DDP, indicating a decreased sensitivity to chemotherapy in TNBC.

Suppression of the AKT pathway restores sensitivity to chemotherapy in TNBC. The present results suggested that treatment with TAX or DDP with or without the transfection of miR-31-5p mimic or inhibitor altered the activity of the AKT pathway. To further investigate the role of the AKT pathway in chemotherapy resistance of TNBC, the AKT inhibitor LY294002 was used to block the AKT pathway, and the effects on chemotherapy resistance in TNBC cells were investigated. First, cells were transfected with miR-31-5p inhibitor for $48 \mathrm{~h}$ and treated with TAX or DDP combined with AKT inhibitor LY294002 $(20 \mu \mathrm{M})$ for $48 \mathrm{~h}$. Then, flow cytometry was performed to detect cell viability. As shown in Fig. 3A, cells treated with a monotherapy of TAX or DDP showed a slight increase of cell apoptosis, as indicated by the number of cells positive for both PI and Annexin-V (apoptotic rates: TAX, 23.8 $\pm 0.46 \%$; DDP, $28.37 \pm 1.12 \%$ ). However, the apoptosis induced by chemotherapy could be attenuated by the inhibition of miR-31-5p following transfection of miR-31-5p inhibitor (apoptotic rates: TAX + inhibitor, 16.2 $\pm 0.46 \%$; DDP + inhibitor, $16.63 \pm 0.4 \%$ ). Interestingly, LY294002 treatment could restore sensitivity to TAX or DDP (apoptotic rates: TAX + inhibitor + LY294002, 24.67 $\pm 0.32 \%$; DDP + inhibitor + LY294002, 32.73 $\pm 1 \%$ ). To investigate the mechanism underlying miR-31-5p function, western blotting was performed to detect the protein expression level of apoptosis and proliferation markers. Treatment with TAX or DDP in cells transfected with miR-31-5p inhibitor induced an increase in P-gp expression. Similar results were found for Bcl-2. However, Bax levels were reduced after treatment with TAX or DDP in cells transfected with miR-31-5p inhibitor. Interestingly, cells treated with LY294002 showed increased levels of Bax compared with monotherapy of TAX or DDP, indicating higher levels of apoptosis were found in the LY294002 group (Fig. 3B). In addition, AKT and p-AKT levels were also investigated. As shown in Fig. 3B, the level of AKT did not change among groups. However, p-AKT levels increased significantly compared with single treatments $(\mathrm{NC}+\mathrm{TAX}$ or $\mathrm{NC}+\mathrm{DDP})$. Consistently, after treatment with LY294002, the expression level of p-AKT was significantly reduced to the expression level in the control group. Collectively, the present results suggested that the apoptosis induced by monotherapy with TAX or DDP could be attenuated by transfection with miR-31-5p inhibitor, and this effect was reversed by treatment with LY294002, an AKT inhibitor.

\section{Discussion}

As an essential chemotherapeutic agent, TAX, also known as paclitaxel, has been used to treat various types of tumors, including non-small cell lung cancer, prostate cancer and ovarian cancer (39-41). However, its clinical efficacy is limited as the chemoresistance of primary tumor cells during the course of treatment was found in a large proportion of patients $(42,43)$. For the treatment of a diverse group of malignancies, including breast, prostate, ovarian, testicular, cervical, bladder, lung cancer and refractory non-Hodgkin's lymphomas, DDP is a widely used chemotherapeutic agent (44). However, resistance to TAX and DDP is found in the late stage of breast cancer and in particular in TNBC.

It has been reported that AKT, a serine/threonine kinase, serves a significant role in cell survival following exposure to apoptotic stimuli $(45,46)$. In breast cancer, constitutive activation of the PI3K/AKT pathway in combination with the upregulation of HER2 and/or loss of PTEN suppressor gene, confers resistance to endocrine therapy including tamoxifen, and EGFR- and HER2-targeted therapies $(47,48)$. In the present study, cell proliferation was found to be suppressed following overexpression of miR-31-5p, and was increased following miR-31-5p inhibitor transfection. Consistently, cell apoptosis was promoted by overexpression of miR-31-5p but suppressed by miR-31-5p inhibition. The present results are in line with prior observations regarding miR-31-5p, and suggested that miR-31-5p may act as a tumor suppressor in breast cancer and in particular in TNBC. TAX and DDP showed no significant inhibitory effects on TNBC cell proliferation. Cells treated with mimic + TAX or mimic + DDP showed higher apoptotic rate than cells treated with only TAX or DDP.

The present results indicated that overexpression of miR-31-5p restored sensitivity to both drugs. Consistently, inhibition of miR-31-5p blocked the effects of the drugs by reducing cell apoptosis. Interestingly, the reduction in the sensitivity to TAX and DDP induced by miR-31-5p inhibition could be restored by inhibiting AKT using LY294002. The $\mathrm{PI} 3 \mathrm{~K} / \mathrm{AKT} / \mathrm{mTOR}$ pathway is frequently activated in breast cancer, and PIK 3 catalytic subunit $\alpha$ was found to be the most commonly mutated gene in ER-positive breast cancer (9). As previously reported, the activation of this pathway has been found to be associated with the resistance to therapies targeting HER2, and endocrine and cytotoxic therapy in breast cancer (48).

As previously reported, miR-31 induces cell apoptosis by downregulating the expression level of Bcl-2 by directly targeting protein kinase $\mathrm{C} \varepsilon$ (PKC $\mathrm{P}$ ) in breast cancer cells (32). $\mathrm{PKC} \varepsilon$ may serve a role in the increased rates of cell apoptosis induced by miR-31-5p and TAX or DDP treatment in TNBC. In addition, $\mathrm{PKC} \varepsilon$ may be involved in the molecular mechanism underlying miR-31-5p-mediated apoptosis regulation.

The present findings suggested that the AKT pathway may be involved in the acquisition of chemotherapy resistance. Therefore, combination of miR-31-5p and AKT inhibitors may enhance efficacy of chemotherapy in breast cancer, and, in particular, in TNBC. However, in order to confirm the present results, mechanistic and clinical studies are required to identify the exact pathways involved in the increased chemosensitivity caused by miR-31-5p. In addition, xenograft models and genetically engineered mouse model may be used in the future to investigate the role of miR-31-5p in vivo. However, the present findings suggest that it is necessary to examine the role and the underlying mechanisms of miR-31-5p in TNBC, and the present results may facilitate the development of using miR-31-5p to regulate treatments in order to enhance therapeutic efficacy in the future.

\section{Acknowledgements}

Not applicable. 


\section{Funding}

No funding was received.

\section{Availability of data and materials}

The datasets used and/or analyzed during the current study are available from the corresponding author on reasonable request.

\section{Authors' contributions}

LD conceived and designed the present study. XS performed cell culture experiments and wrote the manuscript. JL performed western blot and RT-qPCR analyses, and analyzed the data.

\section{Ethics approval and consent to participate}

Not applicable.

\section{Patient consent for publication}

Not applicable.

\section{Competing interests}

The authors declare that they have no competing interests.

\section{References}

1. Fragomeni SM, Sciallis A and Jeruss JS: Molecular subtypes and local-regional control of breast cancer. Surg Oncol Clin N Am 27: 95-120, 2018.

2. Camorani S, Fedele M, Zannetti A and Cerchia L: TNBC challenge: Oligonucleotide aptamers for new imaging and therapy modalities. Pharmaceuticals (Basel) 11: pii: E123, 2018.

3. Dent R, Trudeau M, Pritchard KI, Hanna WM, Kahn HK, Sawka CA, Lickley LA, Rawlinson E, Sun P and Narod SA: Triple-negative breast cancer: Clinical features and patterns of recurrence. Clin Cancer Res 13: 4429-4434, 2007.

4. John EM, Hines LM, Phipps AI, Koo J, Longacre TA, Ingles SA, Baumgartner KB, Slattery ML and Wu AH: Reproductive history, breast-feeding and risk of triple negative breast cancer: The Breast Cancer Etiology in Minorities (BEM) study. Int J Cancer 142: 2273-2285, 2018.

5. Domagala P, Huzarski T, Lubinski J, Gugala K and Domagala W: Immunophenotypic predictive profiling of BRCA1-associated breast cancer. Virchows Arc 458: 55-64, 2011.

6. Sameni M, Tovar EA, Essenburg CJ, Chalasani A, Linklater ES, Borgman A, Cherba DM, Anbalagan A, Winn ME, Graveel CR and Sloane BF: Cabozantinib (XL184) inhibits growth and invasion of preclinical TNBC models. Clin Cancer Res 22: 923-934, 2016.

7. Ouyang M, Li Y, Ye S, Ma J, Lu L, Lv W, Chang G, Li X, Li Q, Wang $S$ and Wang W: MicroRNA profiling implies new markers of chemoresistance of triple-negative breast cancer. PLoS One 9: e96228, 2014.

8. O'Shaughnessy J, Osborne C, Pippen JE, Yoffe M, Patt D, Rocha C, Koo IC, Sherman BM and Bradley C: Iniparib plus chemotherapy in metastatic triple-negative breast cancer. $\mathrm{N}$ Engl J Med 364: 205-214, 2011.

9. Ellis MJ and Perou CM: The genomic landscape of breast cancer as a therapeutic roadmap. Cancer Discov 3: 27-34, 2013.

10. Altundag $\mathrm{K}$ : Is there a role of breast pathologist in diagnostic challenges of discordances in ER, PR, and HER2 between primary breast cancer and brain metastasis? J Neurooncol 138: $219,2018$.
11. Dackus GMHE, Jozwiak K, Sonke GS, van der Wall E, van Diest PJ, Hauptmann M, Siesling S and Linn SC: Optimal adjuvant endocrine treatment of ER+/HER2+ breast cancer patients by age at diagnosis: A population-based cohort study. Eur J Cancer 90: 92-101, 2018.

12. Jung J, Lee SH, Park M, Youn JH, Shin SH, Gwak HS and Yoo H: Discordances in ER, PR, and HER2 between primary breast cancer and brain metastasis. J Neurooncol 137: 295-302, 2018.

13. Di Leva G, Calin GA and Croce CM: MicroRNAs: Fundamental facts and involvement in human diseases. Birth Defects Res C Embryo Today 78: 180-189, 2006.

14. Calin GA, Dumitru CD, Shimizu M, Bichi R, Zupo S, Noch E, Aldler H, Rattan S, Keating M, Rai K, et al: Frequent deletions and down-regulation of micro-RNA genes miR15 and miR16 at 13 q14 in chronic lymphocytic leukemia. Proc Natl Acad Sci USA 99: 15524-15529, 2002.

15. Michael MZ, SM OC, van Holst Pellekaan NG, Young GP and James RJ: Reduced accumulation of specific microRNAs in colorectal neoplasia. Mol Cancer Res 1: 882-891, 2003.

16. Takamizawa J, Konishi H, Yanagisawa K, Tomida S, Osada H, Endoh H, Harano T, Yatabe Y, Nagino M, Nimura Y, et al: Reduced expression of the let-7 microRNAs in human lung cancers in association with shortened postoperative survival. Cancer Res 64: 3753-3756, 2004.

17. Metzler M, Wilda M, Busch K, Viehmann S and Borkhardt A: High expression of precursor microRNA-155/BIC RNA in children with Burkitt lymphoma. Genes Chromosomes Cancer 39: 167-169, 2004.

18. Eis PS, Tam W, Sun L, Chadburn A, Li Z, Gomez MF, Lund E and Dahlberg JE: Accumulation of miR-155 and BIC RNA in human B cell lymphomas. Proc Natl Acad Sci USA 102: 3627-3632, 2005.

19. Singh R and Mo YY: Role of microRNAs in breast cancer. Cancer Biol Ther 14: 201-212, 2013.

20. Deng Y, Bi X, Zhou H, You Z, Wang Y, Gu P and Fan X: Repair of critical-sized bone defects with anti-miR-31-expressing bone marrow stromal stem cells and poly(glycerol sebacate) scaffolds. Eur Cell Mater 27: 13-25, 2014.

21. Stepicheva NA and Song JL: Function and regulation of microRNA-31 in development and disease. Mol Reprod Dev 83: 654-674, 2016.

22. Huang S, Chen Z, Wu W, Wang M, Wang R, Cui J, Li W and Wang S: MicroRNA-31 promotes arterial smooth muscle cell proliferation and migration by targeting mitofusin- 2 in arteriosclerosis obliterans of the lower extremitie. Exp Ther Med 15: 633-640, 2018.

23. Munoz X, Mata A, Bassas L and Larriba S: Altered miRNA signature of developing germ-cells in infertile patients relates to the severity of spermatogenic failure and persists in spermatozoa. Sci Rep 5: 17991, 2015.

24. Kresowik JD, Devor EJ, Van Voorhis BJ and Leslie KK: MicroRNA-31 is significantly elevated in both human endometrium and serum during the window of implantation: A potential biomarker for optimum receptivity. Biol Reprod 91: 17, 2014.

25. Augoff K, Das M, Bialkowska K, McCue B, Plow EF and Sossey-Alaoui K: miR-31 is a broad regulator of $\beta 1$-integrin expression and function in cancer cells. Mol Cancer Res 9: 1500-1508, 2011.

26. Yamagishi M, Nakano $K$, Miyake A, Yamochi $T$, Kagami Y, Tsutsumi A, Matsuda Y, Sato-Otsubo A, Muto S, Utsunomiya A, et al: Polycomb-mediated loss of miR-31 activates NIK-dependent NF-kappaB pathway in adult T cell leukemia and other cancers. Cancer Cell 21: 121-135, 2012.

27. Kim HS, Lee KS, Bae HJ, Eun JW, Shen Q, Park SJ, Shin WC, Yang HD, Park M, Park WS, et al: MicroRNA-31 functions as a tumor suppressor by regulating cell cycle and epithelial-mesenchymal transition regulatory proteins in liver cancer. Oncotarget 6: 8089-8102, 2015.

28. Cottonham CL, Kaneko S and Xu L: miR-21 and miR-31 converge on TIAM1 to regulate migration and invasion of colon carcinoma cells. J Biol Chem 285: 35293-35302, 2010.

29. Xu RS, Wu XD, Zhang SQ, Li CF, Yang L, Li DD, Zhang BG, Zhang Y, Jin JP and Zhang B: The tumor suppressor gene RhoBTB1 is a novel target of miR-31 in human colon cancer. Int J Oncol 42: 676-682, 2013.

30. Liu CJ, Tsai MM, Hung PS, Kao SY, Liu TY, Wu KJ, Chiou SH, Lin SC and Chang KW: miR-31 ablates expression of the HIF regulatory factor FIH to activate the HIF pathway in head and neck carcinoma. Cancer Res 70: 1635-1644, 2010. 
31. Yu M, Liang H, Fu Z, Wang X, Liao Z, Zhou Y, Liu Y, Wang Y, Hong Y, Zhou X, et al: BAP1 suppresses lung cancer progression and is inhibited by miR-31. Oncotarget 7: 13742-13753, 2016.

32. Korner C, Keklikoglou I, Bender C, Worner A, Munstermann E and Wiemann S: MicroRNA-31 sensitizes human breast cells to apoptosis by direct targeting of protein kinase $\mathrm{C}$ epsilon (PKCepsilon). J Biol Chem 288: 8750-8761, 2013.

33. Livak KJ and Schmittgen TD: Analysis of relative gene expression data using real-time quantitative PCR and the 2(-Delta Delta $\mathrm{C}(\mathrm{T})$ ) method. Methods 25: 402-408, 2001

34. Park JH, Ahn JH and Kim SB: How shall we treat early triple-negative breast cancer (TNBC): From the current standard to upcoming immuno-molecular strategies. ESMO Open 3 (Suppl 1): e000357, 2018.

35. Siddiqui WA, Ahad A and Ahsan H: The mystery of BCL2 family: Bcl-2 proteins and apoptosis: An update. Arch Toxicol 89: 289-317, 2015.

36. Lin Y, Kokontis J, Tang F, Godfrey B, Liao S, Lin A, Chen Y and Xiang J: Androgen and its receptor promote Bax-mediated apoptosis. Mol Cell Biol 26: 1908-1916, 2006.

37. Ge C, Cao B, Feng D, Zhou F, Zhang J, Yang N, Feng S, Wang G and Aa J: The down-regulation of SLC7A11 enhances ROS induced P-gp over-expression and drug resistance in MCF-7 breast cancer cells. Sci Rep 7: 3791, 2017.

38. Paplomata E and O'Regan R: The PI3K/AKT/mTOR pathway in breast cancer: Targets, trials and biomarkers. Ther Adv Med Oncol 6: 154-166, 2014

39. Henley D, Isbill M, Fernando R, Foster JS and Wimalasena J: Paclitaxel induced apoptosis in breast cancer cells requires cell cycle transit but not Cdc2 activity. Cancer Chemother Pharmacol 59: 235-249, 2007.
40. Tan M and Yu D: Molecular mechanisms of erbB2-mediated breast cancer chemoresistance. Adv Exp Med Biol 608: 119-129, 2007.

41. Orr GA, Verdier-Pinard P, McDaid $\mathrm{H}$ and Horwitz SB Mechanisms of Taxol resistance related to microtubules. Oncogene 22: 7280-7295, 2003.

42. Frankel A, Buckman R and Kerbel RS: Abrogation of taxol-induced G2-M arrest and apoptosis in human ovarian cancer cells grown as multicellular tumor spheroids. Cancer Res 57: 2388-2393, 1997.

43. Yin S, Bhattacharya R and Cabral F: Human mutations that confer paclitaxel resistance. Mol Cancer Ther 9: 327-335, 2010.

44. Tsimberidou AM, Braiteh F, Stewart DJ and Kurzrock R: Ultimate fate of oncology drugs approved by the us food and drug administration without a randomized Trial. J Clin Oncol 27: 6243-6250, 2009.

45. Song G, Ouyang G and Bao S: The activation of Akt/PKB signaling pathway and cell survival. J Cell Mol Med 9: 59-71, 2005.

46. Wang YP, Huang LY, Sun WM, Zhang ZZ, Fang JZ, Wei BF, $\mathrm{Wu} \mathrm{BH}$ and Han ZG: Insulin receptor tyrosine kinase substrate activates EGFR/ERK signalling pathway and promotes cell proliferation of hepatocellular carcinoma. Cancer Lett 337: 96-106, 2013

47. Tokunaga E, Kimura Y, Mashino K, Oki E, Kataoka A, Ohno S, Morita M, Kakeji Y, Baba H and Maehara Y: Activation of PI3K/Akt signaling and hormone resistance in breast cancer. Breast Cancer 13: 137-144, 2006.

48. Clark AS, West K, Streicher S and Dennis PA: Constitutive and inducible Akt activity promotes resistance to chemotherapy, trastuzumab, or tamoxifen in breast cancer cells. Mol Cancer Ther 1: 707-717, 2002. 